\title{
Entrez Gene
}

National Cancer Institute

\section{Source}

National Cancer Institute. Entrez Gene. NCI Thesaurus. Code C45765.

NCBI's database for gene-specific information. It focuses on the genomes that have been completely sequenced, that have an active research community to contribute genespecific information, or that are scheduled for intense sequence analysis. The content of Entrez Gene represents the result of curation and automated integration of data from NCBI's Reference Sequence project (RefSeq), from collaborating model organism databases, and from many other databases available from NCBI. 